\title{
PROPENSIÓN A APRENDER, MEDIACIÓN Y COMPROMISO DOCENTE
}

Propensity to learn, mediation and teaching commitment

Propensão a aprender, mediação e compromisso docente

\author{
Silvia López de Maturana Luna \\ Universidad de La Serena, Chile. Fono: +56 51 2204478. Correo electrónico: \\ silvialml@gmail.com
}

\begin{abstract}
Resumen
Todos los niños pueden aprender ya que la propensión a hacerlo es una cualidad inherente al ser humano. Ellos aprenderán lo que perciben dentro de su cultura, por eso no da lo mismo quién los educa y en qué ambiente lo hacen. Si hay experiencias de aprendizaje mediado es altamente probable que se generen vínculos seguros entre educadores y niños a partir de la confianza básica en sus capacidades, razón por la cual es una alternativa pedagógica óptima para el desarrollo de su propensión a aprender. Sin embargo, el modelo paradigmático de muchos centros escolares es lineal y obedece a la lógica adulta que aniquila el saber de los niños. Por lo tanto, es indispensable una transformación radical en las formas de enseñar para actualizar la propensión hacia el aprendizaje, lo que implica consecuencias epistemológicas trascendentes para la vida. Podemos partir por observar y escuchar a los niños más allá de las cifras, estándares y categorías, mirar al mundo con otros ojos y evitar, como señala Arendt, banalizar la inequidad y la injusticia para que no parezca natural pensar que no merecemos algo mejor.

Palabras clave: propensión a aprender, mediación, profesionalidad docente, compromiso docente.
\end{abstract}

\footnotetext{
Abstract

All children can learn because the propensity to do it is an inherent quality in the human being. They will learn what they perceive within their own culture, that is why it is not the same who educates them and the environment in what they do it. If there are mediated

Propensión a aprender, mediación y compromiso docente
} 
learning experiences it is highly likely that secure links between educators and children will be generated, based on the basic confidence in their abilities, that is why it is an optimum pedagogical alternative for the development of their propensity to learn. However, the paradigmatic model of many schools is linear and it obeys the adult logic that annihilates the knowledge of children. Therefore, a radical transformation in the ways of teaching is indispensable to update the propensity towards learning, implying transcendent epistemological consequences for life. We can start by watching and listening to children beyond numbers, standards and categories, looking at the world through different eyes and avoiding to trivialize inequity and injustice, as Arendt points out, so that it does not seem natural to think that we do not deserve something better.

Keywords: propensity lo learn, mediation, teacher professionalism, teaching commitment

\section{Resumo}

Todas as crianças podem aprender, pois a propensão a fazê-lo é uma qualidade inerente ao ser humano. Elas aprenderão o que percebem dentro de sua cultura, por isso, quem as educa e o ambiente onde esta aprendizagem ocorre não é indiferente. Se há experiências de aprendizagem mediada é altamente provável que vínculos seguros sejam gerados entre educadores e crianças, a partir da confiança básica em suas capacidades, razão pela qual é uma ótima alternativa pedagógica para o desenvolvimento de sua propensão a aprender. Porém, o modelo paradigmático de muitas escolas é linear e obedece a uma lógica adulta que aniquila o saber das crianças. Portanto, é indispensável uma transformação radical nas formas de ensinar para atualizar a propensão à aprendizagem, o que implica consequências epistemológicas transcendentes à vida. Podemos partir da observação e escutar as crianças para além das notas, normas e categorias, olhar o mundo com outros olhos e evitar, como assinala Arendt, banalizar a iniquidade e a injustiça para que não pareça natural pensar que não merecemos algo melhor.

Palavras-chave: propensão a aprender, mediação, Profissionalidade docente, compromisso docente.

Propensión a aprender, mediación y compromiso docente 
“... que aquel que llega al mundo sea acompañado al mundo y entre en conocimiento del mundo, que sea
introducido en ese conocimiento por quienes le han precedido... que sea introducido y no moldeado, ayudado
y no fabricado" (Meirieu, 2001).

\section{Propensión a aprender}

¿Qué hijos le estamos dejando al mundo? se pregunta Philippe Meirieu en un dejo de perplejidad por el mundo en que vivimos y con la esperanza de que los que aun no nacen, puedan ser educados para hacer del mundo un lugar más habitable. Eso nos lleva a replantearnos la manera en que estamos educando a los niños desde los primeros años y nuestra forma de pensarlos. Pareciera ser que, muchas veces, olvidamos que los entornos en los que transcurre su cotidianeidad impactan directamente en sus aprendizajes. Ningún niño permanece indiferente ante las oportunidades de explorar su entorno, por eso, cualquier interacción o ambiente no da lo mismo en los procesos de aprendizaje. Eso sucede porque los niños, que son alteridad pura, nos interpelan constantemente y perciben el mundo según se lo mostramos, lo que implica la responsabilidad de guiarlos en libertad sin, por ello, renunciar al impacto de nuestra influencia. Se trata de no abandonarlos a su propia suerte ya que lo que ellos aprendan dependerá de lo que les hagamos vivir (Levinas, 2002; Meirieu, 2010; Arendt, 2016).

Qué duda cabe de que todos los niños propenden a aprender, informal y caóticamente a través de lo que ven, escuchan, tocan, huelen y gustan, que se atraen por las fronteras, lo imprevisto, la exploración y los desafíos. En ese contexto, el asombro, la curiosidad, las preguntas y el juego son, entre otros, atractores que forman patrones y definen la asombrosa y genuina complejidad infantil, que no encontramos en otra etapa de la vida ${ }^{1}$.

La propensión a aprender es una cualidad inherente al ser humano, aleatoria e imprevista, que tiende a autoorganizarse permanentemente a pesar de no seguir un orden regular. Para eso los niños necesitan entornos gratificantes donde puedan expresarla

\footnotetext{
${ }^{1}$ Proyecto de investigación FONDECYT (Fondo Nacional de Investigación Científica y Tecnológica) No 1110577, titulado Asombros educativos infantiles y propensión a aprender.
}

Propensión a aprender, mediación y compromiso docente 
libremente.

Desde los primeros años de la educación formal quiénes educan creen saber lo que quieren o necesitan los niños, planifican estrategias de interacción y atribuyen significado a los estímulos que, muchas veces, ni siquiera se acercan a lo que los niños perciben o a lo que les interesa. Ello, en el peor de los casos, los vuelve sumisos y aniquila la necesidad de aprender. Gran error cometemos si creemos que sabemos lo que le depara a los niños porque está escrito en un programa o en un manual. Por eso necesitamos atender más a la percepción de la infancia que solo al concepto y más a la vida que al mundo, para quitarnos el lenguaje técnico, poderoso, sancionador y determinista (Skliar, 2010).

La infancia no es solo una etapa en la vida que da paso a la siguiente, sino que es una categoría antropológica que emerge siempre que aprendemos cosas nuevas, por eso deberíamos mantenerla. Si siendo adultos disfrutamos, gozamos y nos asombramos en el devenir cotidiano, estamos reviviendo la infancia porque somos y estamos en un lugar, en un tiempo y espacio que sentimos propio y que tiene sentido en sí mismo. Por lo tanto, dada su propia energía y dinamismo, la infancia no puede ser solo preparatoria para otra etapa (Arendt, 2016; Skliar, 2010), lo que significa valorar ese tiempo tal cual se muestra y ofrecer las posibilidades para que la propensión a aprender se desarrolle.

Los niños son la mixtura perfecta entre lo potencial y lo posible, exploran, juegan con toda su fisiología y se complacen en ella (experimentum potentiae, Agambem, s/r), crean sus propios mundos poniendo en juego el máximo de su potencial cognitivo y caminan desacompasadamente, como dice Walter Benjamin (en Skliar, 2010) hasta que un adulto les señala la línea recta por la que deben hacerlo. Eso nos lleva a preguntarnos: ¿cuánto de lo que les enseñamos es necesario?, ¿en qué basamos nuestras preconcepciones, valores, convicciones?, ¿qué creemos que es lo que los niños necesitan?

Cuando un niño quiere saber algo, no aspira más allá de la pregunta simple porque posteriormente la complejizará en la medida que aumente su conocimiento. Ese proceso siempre oscila entre lo simple y lo complejo, pero debemos cuidarnos de confundirlo con lo superficial y lo complicado (López de Maturana, 2015 a). 
¿Qué relaciona Gustavo, de dos años, cuando ese día de mucha neblina no ve el mar al pasar por el camino acostumbrado y le dice a su madre: "le sacaron el tapón"? ¿Comprenderá que ha hecho una analogía con el lavamanos?, ¿qué aprenderíamos si pudiéramos conocer y analizar toda la información que Gustavo posee y maneja cuando establece ese tipo de relaciones?, ¿qué sabríamos respecto a las funciones cognitivas que utiliza para realizar inferencias lógicas o relaciones virtuales?, ¿qué experiencias mediadoras tiene en su hogar? Quizá no tengamos respuestas si es que no nos hacemos preguntas y si es que no escuchamos a los niños.

Los buenos educadores entienden que la experiencia infantil es juego y asombro permanente. Están preparados con el rigor propio del científico y la emotividad del artista, gustan de su trabajo y no sólo cumplen con las características, entre otras, de "amables", "activos", "responsables" que comúnmente se les atribuye, sino que están convencidos de la capacidad de cada uno de los niños a los que educan (López de Maturana, 2016). Quienes no lo son, repiten rutinas, no ven los rostros de los niños ni escuchan sus subjetividades, los objetivan y separan de su propio mundo. No le dan crédito a la propensión a aprender y se rinden fácilmente ante la primera dificultad aduciendo que "es una cuestión de raza, genes, herencia" (Feuerstein, 1991). Se convencen de que esos niños no van a aprender por más esfuerzos que realicen y terminan por convencer a ellos de lo mismo.

De esa manera, los niños aprenden a desacralizar su existencia sin tener responsabilidad por las causas que la generan. El miedo, las dificultades, el dolor, la pobreza y tantos otros, terminan por ser estados permanentes que cuesta mucho resacralizar. Por eso es fundamental la igualdad desde el punto de partida para que los niños sientan confianza y seguridad en sus potencialidades desde los primeros años y no crezcan indefensos y vulnerados.

La convicción y postura optimista de los educadores es fundamental para dar sentido al proceso educativo y trae consigo consecuencias epistemológicas determinantes para la vida de los niños. Por lo tanto, qué y cómo aprenden los niños, cuál es mi postura frente al aprendizaje y a la enseñanza, desde dónde hablo?, ¿desde lo declarativo o desde Propensión a aprender, mediación y compromiso docente 
las relaciones?, ¿desde el dispositivo estandarizado o desde el reconocimiento del otro?, se tornan preguntas relevantes para todo educador.

Los niños naturalmente propenden a aprender y culturalmente aprenden dentro del entorno en el que conviven con otros que les son significativos. Ese es un proceso, de suyo, complejo que necesita de mediadores significativos que trasciendan la mera relación de los niños con su entorno, pero con tal sutileza para que no los apabullen con normativas ni los dejen al libre albedrío. Los mediadores, determinantes proximales del aprendizaje, comparten con los niños sus posibilidades de acción, observan, escuchan y están atentos cuando éstos los necesitan y se alejan cuando su presencia los inhibe.

Si los niños aprenden en un ambiente activo modificante, su propensión a aprender se activará con más fluidez que si lo hacen en un ambiente pasivo aceptante, donde es altamente probable que la anquilosen. En el primer caso, se requiere del compromiso mediador, personal y profesional, de toda la familia y comunidad educativa.

\section{Mediación}

La mediación más que una estrategia de enseñanza y de aprendizaje es una filosofía de vida que genera vínculos seguros entre educadores y niños, que parte desde la confianza básica en los primeros años hasta los últimos niveles del desarrollo del ser humano. Implica una visión optimista en las capacidades de todos los niños, razón por la cual es una alternativa óptima para el desarrollo de su propensión a aprender. En ese proceso el mediador es intencional, insistente, paciente y da sentido a sus enseñanzas para que éstas sean trascendentes. Está atento a los cambios sutiles de los niños para identificar las dificultades que necesitan apoyo, creando ambientes activo modificantes para que puedan transferir lo aprendido a nuevas situaciones de aprendizaje (López de Maturana, 2015 a).

En caso contrario, la tierra es fértil para generar ambientes pasivo aceptantes, escolarizantes, homogéneos, donde la intervención está ligada solo a las necesidades inmediatas, donde las alternativas pesimistas dan pocas posibilidades de éxito a los niños, donde se ignora la pregunta y se fragmenta la realidad.

El nivel de educación parvularia, dado los principios que lo rigen, favorece las 
instancias de activación de la propensión a aprender porque aun no se escolariza, a pesar de que, en ocasiones, se observan prácticas pedagógicas rutinarias y acomodaticias que favorecen un tipo pasivo de planificación, acción y evaluación. Por lo tanto, es indispensable una transformación radical de las formas de enseñar para actualizar la propensión hacia el aprendizaje de los niños y de las niñas.

La propensión a aprender favorece la modificabilidad cognitiva, entendida esta como un cambio estructural en los patrones de desarrollo cognitivo (Feuerstein, 1991) que no es predecible, por lo tanto no tiene que ver con la evolución biológica; es un fenómeno que corresponde a la propensión natural del ser humano a adaptarse (no a someterse) y a recrear su realidad. Por eso tiene una connotación más profunda que la de un simple cambio, porque, entre otros, es interna y altera el curso de desarrollo cognitivo del propio organismo, sus habilidades, capacidades, rasgos de personalidad, y competencias (López de Maturana, 2015 a).

Muchos creen que enseñar a los niños es una tarea fácil que cualquiera puede hacer porque los perciben indefensos e inacabados. Quienes así lo piensan desconocen las especificidades propias de los niños y de la tarea profesional de quiénes los educan, lo que implica la responsabilidad de educar en y para la vida diversa, movilizar conocimientos, convicciones, estrategias y métodos para saber decidir y actuar de manera autónoma y emergente. Una manera de enseñar de manera significativa es a través de la Experiencia de Aprendizaje Mediado (Feuerstein, 1991), que abre posibilidades para actualizar las capacidades de los niños, aprovechar las experiencias de su entorno y situarlos en su propia cultura, lo que se consigue gracias a la intencionalidad del mediador para lograr la reciprocidad de los niños al encantarse con el aprendizaje, el sentido que le dan a cada experiencia y la trascendencia que se logra cuando los niños llegan a ser pensadores autónomos.

Por lo tanto, el ser humano desde sus primeros años necesita de un adulto que lo guíe, siendo la familia, las/os educadoras de párvulos y luego los/as profesores los principales soportes educativos y formales en los primeros años de vida, de quiénes dependerá enriquecer o anquilosar la curiosidad epistemológica características de los niños Propensión a aprender, mediación y compromiso docente 
en esas edades.

Hanna Arendt (2016) señala que la educación es el lugar donde decidimos si amamos al mundo lo bastante como para tomar una responsabilidad por el y transmitirlo a nuestros descendientes. Agrega que cada vez que un niño llega al mundo tenemos que saludarlo cual salvador y darle la hospitalidad que merece, porque su nacimiento trae la esperanza de un comienzo radical y de un signo de que, todavía, todo puede suceder. Eso nos lleva a asegurar que la educación es una promesa a futuro, un proyecto para incrementar la humanidad, por lo tanto, es un acontecimiento ético (Bárcena y Mèlich, 2014).

El compromiso ético con nuestra tarea educativa se expresa, entre otros, a través de lo que pensamos que podemos hacer gracias al dominio de destrezas en nuestro campo, de cómo ejercemos el liderazgo y para qué fines, de la capacidad de compartir con los otros y de cómo colaborar y aconsejar en aquello que mejor dominamos para enriquecer los procesos de conocimiento (Hargreaves, 1999). Como ya se ha señalado, dicho proceso comienza desde que los niños se incorporan al mundo, manipulando objetos, explorándolos activa y sensorialmente, al tiempo que se relacionan con otros niños y adultos de su entorno. Los educadores debieran observar y escuchar permanentemente a los niños para aprender de ellos.

\section{Profesionalidad docente}

"La profesionalidad no constituye el estado final al que se encaminan las ocupaciones; es más bien un proceso continuo en persecución de un ejercicio útil y responsable de la misma" (Darling-Hammond, 2001: 375).

Caracterizar y definir la profesionalidad docente es una tarea compleja que no solo requiere revisar diversas teorías sobre el tema sino también considerar las percepciones de la opinión pública y analizar las propias creencias del profesorado. Como sea, el rol docente es una tarea profesional que requiere de exigencia y compromiso en la propia práctica pedagógica y de satisfacción y libertad al ejercerla. 
No se puede negar que la profesión docente ha sido desvalorada por diversos sectores de la opinión pública, lo que refuerza el estereotipo desprofesionalizador que favorece la repetición y mecanización de las prácticas pedagógicas en detrimento del desarrollo de la propensión a aprender de los niños (López de Maturana, 2016). Por eso, pensar la educación desde nuestro rol docente implica establecer relaciones y analizar las concordancias o discrepancias entre lo que pensamos, decimos y lo que realmente hacemos al interior de nuestras prácticas, es decir, saber y comprender qué, cómo, por qué y para qué hacemos lo que hacemos. La comprensión del proceso educativo pasa obligadamente por entender qué es lo que logran llevar a la acción los educadores de todo aquello que piensan, cómo lo llevan a cabo y qué aprenden de todo lo que enseñan (Ibid, 2015), y por preguntarnos si formamos para la sumisión o para la autonomía (Martínez Bonafé, 2005). La respuesta a estas inquietudes dependerá de qué entendemos por educación y cómo y desde dónde miramos a los educandos.

El rol profesional lo vamos construyendo a lo largo de un continuum histórico, no ajeno a discontinuidades significativas dado su carácter de público, institucionalizado y sostenido por un complejo entramado de relaciones educativas formales e informales. Es allí donde se forja la identidad profesional que surge de la dialéctica entre quiénes educan y la sociedad en la que se encuentran inmersos (Berger y Luckmann, 1999). Si la reducimos a su expresión formal, la identidad profesional será solo declarativa, lo que tiene como consecuencia no sentirse partícipe de una identidad común. Si, por el contrario, la consideramos en su complejidad educativa sinérgica, el sentido de pertenencia a un grupo identitario será genuino y estimulante. Eso es relevante para entender las participación de los educadores en la formación de los niños ya que si no hay una participación consciente, lo más probable es que haya sometimiento a los acuerdos estructurales alienantes "que dominan incuestionablemente la vida cultural, en este caso la vida escolar que comprende las prácticas cotidianas sobre la enseñanza y, por ende, los curricula” (Apple, 1986:s/r). Si así fuese, los jardines infantiles y las escuelas pasarían a ser una maquinaria burocrática donde la voz de los educadores tiene poca o ninguna autoridad para crear, innovar o generar transformaciones, lo que repercute en la invisibilización de los niños. 
Los educadores que terminan sometiéndose ante un deber ser teórico y estandarizado, derivan hacia posturas pedagógicas anquilosadas que objetivan las conductas de los niños de acuerdo a una pauta, a un periodo crítico o un estadio del desarrollo, sepultando, así, la propensión a aprender de los niños. Los multivariados procesos de aprendizaje terminan por ser unívocos y uniformes, forzando a la subjetividad propia de cada ser para que calce en espacios y tiempos predeterminados. De esa manera, los insondables y espontáneos derroteros del ingenio, la creatividad y las inquietudes de los niños corren el riesgo de transformarse en secuencias lineales y causales.

El modelo paradigmático de los centros educativos con esa concepción lineal obedece a la lógica adulta que no forma parte del saber de los niños. Como es simbólicamente violento, termina, en muchos casos, por convencer a educadores y educandos de que hay personas que pueden aprender y que otras no.

\section{Compromiso pedagógico}

El compromiso pedagógico contribuye a revertir la desvalorización de la profesionalidad docente que se produce por la acción de aquellos educadores repetidores, mecanicistas, rígidos y frontales, cuyas prácticas artificiales, sin entusiasmo y enajenadas, los relegan, junto a sus alumnos, al papel de meros espectadores del proceso educativo (López de Maturana, 2016). El compromiso necesita de la conformación de equipos de trabajo que crean en un proyecto común y cuya convicción sobre la propensión a aprender de los niños no se cuestione. Es distinto decir que hay un niño que no puede aprender a decir que hay un niño que tiene resistencia a aprender. En el primer caso, se atribuye incapacidad al niño, lo que hace bajar las expectativas sobre sus posibilidades de aprendizaje. En el segundo caso, se atribuye capacidad aunque se observe lo contrario, y significa un desafío para los educadores que deben buscar diversas alternativas de acción. Por lo tanto, hay más posibilidades de que la cooperación se vuelque hacia un proyecto creativo común que permita actuar de manera responsable y participar "de los mismos valores y deseos fundamentales al mismo tiempo que vivir en el mismo espacio de acciones básicas" (Maturana, 1992).

Propensión a aprender, mediación y compromiso docente 
Asumir el compromiso para ejercer la libertad pedagógica que los educadores poseen en el aula y ser capaces de revertir, aunque sea parcialmente, la situación particular de su enseñanza y del aprendizaje de los niños, significa que mientras la escuela se empecina por conservar muchas características que no los favorecen, dentro del aula ellos pueden encontrar o crear las herramientas necesarias para provocar los cambios que se requieren (López de Maturana, 2016).

El compromiso pedagógico implica, por una parte, la responsabilidad por lo que se hace y por lo que no se hace, y por otra, examinar y preguntarse qué pasa con la propia experiencia, la que, de acuerdo con Larrosa (2014), no es algo que "pasa frente a mi" sino "lo que me pasa a mí" en relación a los acontecimientos externos. Es aquello que provoca en los educadores la sensación permanente de desafío y emoción por la responsabilidad que les incumbe de educar a los niños, sin que nadie haya tenido que decretarlo, pues trasciende lo que hacen (Levinas, 2002).

Queremos, entonces, una escuela que sea segura para todos, que no legitime arbitrariedades culturales como la exclusión, que sea grata para querer acudir a ella, habitable para estar confiados y amable para que deje huellas profundas en la vida de los niños. Que muestre claramente ambientes de diversidad para que los niños puedan manifestarse en todas sus expresiones, donde encuentren mayor conexión con su vida cotidiana y puedan compartir y jugar. Donde los tiempos y espacios se aprovechen con alegría y optimismo, los valores no se vulneren y la enseñanza se entienda como una tarea profundamente moral y ética de educar a todos los seres humanos (López de Maturana 2015 b).

Queremos que los que vienen a la vida y al mundo que les dejamos, puedan vivir una vida y un tiempo dignos, un mundo en el que no les dé vergüenza vivir (Larrosa, 2006), donde la educación no la pre-fabriquemos (Meirieu, 2010) y donde los cuerpos dejen de ser dóciles, ineptos y sumisos (Focault, 2002).

Por lo tanto, una de nuestras tareas urgentes es observar y escuchar a los niños más allá de los estándares y categorías pre-establecidas para arrancarlos de la lógica de la vida 
humana (Skliar, 2013). Eso implica poner en tela de juicio a los actuales modelos subyacentes y condicionantes que, cual método de control, confabulan en una relación de docilidad-utilidad en los procesos educativos. Acojamos la propuesta de Hanna Arendt (2016) de mirar al mundo con otros ojos para no banalizar la inequidad y la injusticia, y para que no parezca natural pensar que no merecemos algo mejor.

\section{Referencias bibliográficas}

Agamben, G. Por una filosofía de la infancia. s/r

Arendt, H. (2016). Entre el pasado y el futuro. Buenos Aires: Paidós.

Bárcena, F, y Mélich, J.C. (2014). La educación como acontecimiento ético. Buenos Aires: Miño y Dávila.

Feuerstein, R. (1991). Mediated Learning Experience (MLE). Theoretical, Psichosocial and Learning Implications. London: Freund Publishing House Ltd.

Focault, M. (2002) Vigilar y castigar. Buenos Aires: Siglo XXI.

Larrosa, J. (2006). La experiencia y sus lenguajes. Localización: Estudios filosóficos,

ISSN 0210-6086, 55, 160, 2006, 467 - 480.

Levinas, E. (2002). Totalidad e infinito. Salamanca: Ediciones Sígueme.

López de Maturana, S. (2016) Los buenos profesores: Educadores comprometidos con un proyecto educativo. $3^{\text {a }}$ edición. La Serena: Universidad de La Serena.

López de Maturana, S. (2015 a) Maestros en el territorio. 2a edición. La Serena: Universidad de La Serena.

López de Maturana, S. (2015 b) Inclusión en la vida y la escuela: Pedagogía con sentido humano. $2^{\text {a }}$ edición. La Serena: Universidad de La Serena.

Meirieu, P. (2010). Una llamada de atención: Carta a los mayores sobre los niños de hoy. Barcelona: Ariel.

Meirieu, P. (2001). Frankenstein educador. Barcelona, Laertes. 
Skliar, C. (2010). Mirar la infancia por lo que es. Recuperado del 1 de marzo 2010. Subido por Portal @prender - Entre Ríos https://www.youtube.com/watch?v=JTi5OsOqJUc

Skliar, C. (2013)-Parte 1-Entre Comillas- Autores que nos interpelan.

https://www.youtube.com/watch?v=-z0eqA8h9-E. 12 ago. 2013 - Subido por Entre comillas

Skliar, C. Infancia y discursos sobre la niñez. Trazos de una relación sin rumbo.

(FLACSO/CONICET) https://docs.google.com/document/d/1VksRE-T_3.../edit 